\title{
LOS PROYECTOS CONSTITUCIONALES DE 1855: EL CAMINO A LA CONSTITUCIÓN DE 1856 Y LA MODERNIZACIÓN ECONÓMICA
}

\section{THE CONSTITUTIONAL PROJECTS OF 1855: THE PATH TO THE CONSTITUTION OF 1856 AND THE ECONOMIC MODERNIZATION}

\author{
José Carlos Jiyagon Villanueva \\ Universidad Nacional Mayor de San Marcos \\ *Artículo basado en la tesis de maestría del autor \\ Licenciado en Historia por la Universidad Nacional Mayor de San Marcos, Docente del Programa de Estudios Generales de la Universi- \\ dad de Lima, Perú
}

Correo del autor: varayoc@outlook.com

[Recibido: 02/12/2017 Aceptado: 10/04/2018]

\section{RESUMEN}

El objetivo del presente artículo es mostrarnos el camino que se tuvo que desarrollar para establecer la Constitución de 1856, primero se establece las condiciones que pusieron en tela de juicio la Constitución de Huancayo, observando su marcado conservadurismo. Después del triunfo de la revolución de 1854, triunfaron las ideas liberales los cuales se van a plasmar en el debate constitucional de la Convención Nacional de 1855. El bienio 1855 y 1856 será marcado por una serie de publicaciones que buscan influenciar en la elaboración de la Constitución de 1856. Dentro de todo este panorama el norte es la modernización económica del Estado Peruano del siglo XIX.

Palabras clave : Constitución, liberalismo, prensa, descentralización, Estado.

\begin{abstract}
This article shows us the path that had to be developed to establish the Constitution of 1856 , first establishing the conditions that questioned the Constitution of Huancayo, observing its marked conservatism. After the triumph of the revolution of 1854, liberal ideas triumphed which were reflected in the constitutional debate of the National Convention of 1855. The 1855 and 1856 biennium would be marked by a series of publications that sought to influence the development of the Constitution of 1856 . Within all this panorama the north is the economic modernization of the Peruvian State of the XIX century.
\end{abstract}

Keywords : Constitution, liberalism, press, decentralization, State.

\section{INTRODUCCIÓN}

Para estudiar la modernización del Estado peruano, es preciso esperar a la segunda mitad del siglo XIX, donde el triunfo de los ideales liberales permitió desarrollar una serie de reformas en el país, que apuntaban a modernizar la estructura política y económica, para concretar dicho fin, se hacía indispensable el cambio constitucional (Ramos Nuñez, 1993). Para los diferentes Estados del siglo XIX, la elaboración de las Constituciones se hacían necesarias, ya que en ella encontramos los ejes programáticos de lo que apunta los organizadores de los nacientes Estados (Rey de Castro, 2010). Un factor determinante para llevar a cabo el programa de la «Modernización Tradicionalista» (De Tragzenies, 1992) es acabar con la precariedad de las instituciones del Estado.

Los constantes enfrentamientos internos imposibilitaban la construcción de un Estado sólido, aquejado por numerosas pugnas militares. Esta situación llevó como se muestra en la investigación, a promover una política conservadora y centralista, que se plasmó en la Constitución de 1839 
(Basadre, 1994). Durante el gobierno de Echenique se incubo los efectos de la revolución liberal de 1854, el cual fue de gran trascendencia, ya que estimulada por el triunfante liberalismo del siglo XIX, desencadeno grandes transformaciones en la República (Ferrero, 2003).

Los proyectos que se elaboraron impulsaron reformas políticas y económicas, que se plasmaron finalmente en la Constitución de 1856. En ese sentido la transformación de la economía del país, iba por desmontar todas las posibles trabas que obstaculizaban la modernización de la economía del país (Sobrevilla, 2005). Esa situación conlleva a explorar como por aquellos años se produce un cambio que logra romper las políticas comerciales tradicionales, que eran proteccionistas, abriéndose el camino a una economía liberal que fomentó la exportaciones (Gootenberg, 1997).

Este trabajo se justifica en la necesidad de conocer el desarrollo de la institucionalidad política y económica y estas van de la mano junto con la promoción de la ideología liberal, se necesitaba un Estado que proteja la ciudadanía, sea ordenado racionalmente, así como también, la gestión económica debe destrabar el acceso a la tierra que estaba en manos de sectores no progresista, como la Iglesia (García Jordán, 1991), por ello es importante conocer qué proyectos constitucionales se presentaron, ya que en ello encontraremos las propuestas las propuestas que buscan la modernización del Estado.

Un aspecto importante de la modernización es el desarrollo económico del aparato estatal, donde era importante liberalizar la economía, quitarle los ajustes de un Estado que impedía el libre comercio (Gootenberg, 1997) trabando el desarrollo económico, situación que recién se cortara con la expansión del gasto estatal gracias a los recursos guaneros.

Para consolidar la nueva estructura política, era indispensable sostener el sistema representativo, ya que de esta manera se aseguraba la voluntad de las respectivas poblaciones. Por ello, tenía que promoverse el equilibrio de poderes, el cual debía estar establecido en la Constitución, la idea era impedir las constantes fricciones y discusiones entre el poder Ejecutivo y el Legislativo; solo de esta manera se conseguiría el establecimiento del orden. La justificación de la búsqueda del orden, fue tomado de Benjamín Constant, el cual fue utilizado por los ideólogos del conservadurismo hispanoamericano. En el convictorio de San Carlos centro del conservadurismo en el país, era importante su lectura; ya que se destacaba de la idea del poder conservador, el cual servía como sostén ideológico de la clase política, su meta: “[proteger] al gobierno cuando los gobernantes se encontraban divididos y al pueblo de los abusos del gobierno" (Barron 2002, p. 265).

Los legisladores de 1839 imbuidos en ese afán de imponer estabilidad al país tras los episodios de la Confederación y de los primeros años de la república, deseaban ajustar y perfeccionar un poder Ejecutivo consciente de las realidades del país y que además sintonice con los verdaderos deseos de los ciudadanos. Solo de esta manera se podía articular la construcción de un estado moderno.

El estudio permite asegurar que los criterios que se tomaron en cuenta para asegurar el orden, era la construcción de la ciudadanía, esta era necesaria para sustentar el proyecto del país; en donde también las instituciones debían cumplir su rol en estas transformaciones. Los ciudadanos que participen en la construcción del nuevo orden deben ser protegidos, es por ello que los distintos proyectos que se van a elaborar aseguraran las garantías individuales para consagrar la acción de los ciudadanos. También debía asegurarse que la parte religiosa apoye estas ideas. Lo podemos apreciar en el siguiente párrafo:

«(La constitución) es la piedra angular del edificio social; que pierda su nivel, que se descantille, y el edificio bambolea, se hace inseguro. Cuanto más civilizado un pueblo, tanto más celoso es de inmunidad de su Carta Fundamental... (Espinoza, 1855)».

Por ello, la construcción de una nación estable, junto a una ciudadanía responsable, con instituciones que aseguren el orden del Perú, ha sido parte de los objetivos de los distintos grupos políticos que participan en la vida política del país durante la segunda mitad del siglo XIX. Desde mediados de la década de 1840, el Estado nacional se encontraba con la posesión de los recursos guaneros lo que le permitió la posibilidad de potencializar las capacidades financieras que hasta ese momento había sufrido una constante falta de liquidez en las arcas nacionales. La situación del Estado peruano es diferente a décadas anteriores y los actores políticos estaban de acuerdo con el establecimiento del orden que debía estar en consonancia con las ideas de modernidad y progreso que se tiene para esos momentos.

El problema que tenemos es la problemática que aquejó la situación económica y financiera el mismo que concitó la atención de la Convención Nacional, este fue el problema de la 
moneda feble que, durante la etapa del funcionamiento de aquella institución, ocasionó grandes dolores a la economía y finanzas del país.

El estudio realizado ha seguido el método científico con un conjunto de pasos ordenados que se empleará principalmente para hallar nuevos conocimientos en las ciencias. Este trabajo de Investigación se basa en lo empírico y en la medición, sujeto a los principios de las pruebas de razonamiento persiguiendo el tipo investigación histórica, descriptiva y analítica, ya que con ellos se buscaba comprobar de qué manera el Estado había seguido por unos caminos complicados, la ausencia de un orden adecuado y la falta de una estructura sólida llevo a realizar importantes propuestas. La construcción del Estado es una de las ideas que toma una mayor consistencia a mediados del siglo XIX, por ello había que buscar, en primer lugar el orden institucional; inmediatamente debía implementarse las reformas económicas, que permitieran liberalizar la economía del país.

En el trabajo se utiliza el enfoque cualitativo, para explicar cómo el Estado peruano de mediados del siglo XIX, desarrollo propuestas de modernización constitucional. También utilizamos el enfoque cuantitativo, para demostrar cómo el comercio internacional posibilito el incremento de los ingresos, coyuntura que le permitió impulsar la política económica de apertura liberal.

Los resultados se exponen en los siguientes puntos:

Análisis de la precariedad de la institucionalidad política peruana

Desde la promulgación de la Constitución de 1839, se lanzaron constan- tes críticas; situación que se corrobora con la constante inestabilidad política que aquejo al país en la primera parte de la década de 1840: la muerte de Gamarra en Ingavi y la posterior anarquía militar, posibilitaron este ambiente político cargado de tensiones contra el Ejecutivo. En esta circunstancia, las críticas y desazón hacia la carta constitucional de 1839 eran constante, pues era acusada de perennizar y eternizar el autoritarismo de los militares, que su despotismo y arbitrariedades llevaron al Estado a una situación caótica. La crítica que planteaban los liberales, era que la Constitución dificultaba el funcionamiento del Estado peruano, obstaculizando el desarrollo del país (Ulloa, 1853, pp. 13-14). Las mayores críticas que se hicieron a esta carta constitucional, giraba contra el excesivo poder que le otorgaba al presidente de la República, el cual poseía demasiadas facultades, los demás poderes del Estado quedaban sujetos al Ejecutivo; además se condenaba el hecho de que no se había discutido convenientemente cada uno de los artículos. Otra de las acusaciones que se hicieron contra aquella constitución, es que fue forjada por personas sin ideales, ni principios, ni trayectoria. La situación política y económica del país, después de la caída de la Confederación Perú Bolivia, ameritaba este autoritarismo y centralismo, ya que se buscaba evitar la secesión del sur del país.

La Constitución de Huancayo implementada en 1839, tenía mucho que legislar y censurar a su vez. De allí que las críticas contra esta carta sean constantes, especialmente de los elementos liberales quienes aducían sus falencias y limitaciones; además, se imputaba que la Asamblea de Huancayo fue elaborada por personas que carecían de ideas reformistas. Esta crítica debía ser tomada con mucho cuidado, pues no se debe olvidar que la Constitución de 1839 respondía a las necesidades de la época. Las circunstancias políticas determinaron que esta carta magna dure mucho más tiempo que las otras (tuvo vigencia desde 1839 a 1854).

Uno de los críticos fue el general Vivanco, quien denuncia esta infortunada situación, que a pesar de ser considerado parte del estamento conservador, presentaba un programa que establecía planteamientos revolucionarias (se acercaban mucho más a los planteamientos de los liberales): como el voto universal directo, defensa de la descentralización política y administrativa; pretendía que la representación política del congreso fuera proporcional con respecto al número de pobladores de sus provincias. (Del Águila, 2013, p. 129). Las críticas a esta constitución de 1839 se manifiesto con mayor dureza durante el impopular régimen de Echenique. El asunto que hizo notar a la ciudadanía sobre las limitaciones de esta constitución, fue el problema que estallo entre el ciudadano Domingo Elías y el presidente general José $\mathrm{Ru}$ fino Echenique. El escenario reflejó la precariedad de las normas del Estado peruano, se corroboraba una vez más, que la teoría va por camino diferente que el de la práctica; situación que había sido reclamada por Toribio Pacheco en su obra Cuestiones Constitucionales (Pacheco, 1854, pp. 48 - 49).

Análisis de las propuestas presentadas para la Constitución de 1855

Durante el estallido de la revolución moralizadora de 1854 aparecieron numerosos escritos que empezaron a reclamar como debe organizarse el país para un mejor desenvolvimien- 
to de la institucionalidad, muchos de estos escritos están guiados bajo las banderas del liberalismo que buscan imponer un orden definitivo, para así poder iniciar una nueva etapa de prosperidad. Para consolidar las nuevas ideas, era necesario que estas estas propuestas se logren plasmar en leyes que organicen la república y establezcan las bases de los derechos políticos de los ciudadanos, para ello era necesario el establecimiento de una nueva Constitución, por ello Felipe Masías nos dice:

La constitución política debe ser aceptada por todos o al menos por la mayoría de los individuos que componen un país, a fin de que sus preceptos sean obligatorios, pues no siendo estos preceptos sino leyes, se requiere para su existencia y observancia la aceptación del pueblo, que en este caso debe ser expresa, puesto que dicho consentimiento es condición en que estriba la fuerza obligatoria de las leyes (Masías, 1855, p. 59).

Por ello el deseo de poder articular estas ideas en la nueva constitución, permitieron que surgieran una serie de destacados personajes, que, para mediados del siglo XIX, nos plantearon sus visiones e ideales sobre cómo organizar el país. Se destaca la figura de José María Quimper, destacado político liberal arequipeño, que en 1854 escribe el texto: «Instrucción política y reformas para el pueblo. Obra dedicada a las masas del Perú (1854), donde se presenta una justificación sobre la revolución y los beneficios que espera conseguir para el pueblo con estos cambios, para ello hay que alejar del poder a los militares, los cuales son acusados de habernos llevado a este calamitoso estado.

La idea de la Libertad en la clase intelectual peruana
La revolución moralista de 1854 era para los liberales la lucha por imponer en el país la democracia liberal. Los ideales democratizadores de 1848 habían llegado al país, por ello plantean que se debe realizar un cambio en las instituciones y que estas deben acoplarse a los nuevos tiempos. Un factor clave que haría relevante estas transformaciones es el establecimiento de los derechos políticos de los ciudadanos, estos deben ser irrenunciables en esta nueva etapa. Hay toda una serie de ideas que deben ser realmente conocidas por los peruanos: la opinión, la soberanía, la libertad, el progreso público, entre otros.

La opinión es uno de los pilares claves para poder transformar a la sociedad, esta situación se dará cuando los pueblos se organicen y creen espacios para conocer, reflexionar y debatir sus distintos intereses. Esta situación llevaría al pueblo a poder articular sus derechos y evitar que gobiernos ajenos a su voluntad, traten de someterlos a su control. Por ello se hacía necesario que la sociedad civil pueda manifestar con claridad sus ideas, para poder forjar su opinión, solo así podrá alcanzar el progreso político y material. (Quimper, 1854, pp. 10 11).

Todos los individuos tienen el deber de ejercer su opinión y manifestarse si sus libertades son amenazadas, por ello, si se aprecia que las instituciones ya no cumplen sus funciones de satisfacer sus necesidades y las de los demás, era necesario que manifiesten su opinión, pues solo de esa manera las instituciones puedan cambiar. Por ello los individuos de la sociedad deben expresar sus opiniones y críticas a las coyunturas de injusticia, marginación y explotación, solo así surgirán corrientes de opinión en todo el país, que obligaran a impulsar cambios racionales, que expresen la verdadera voluntad de la sociedad civil. Para poder llegar a este punto, de contar con una opinión incisiva, se tenía que crear las condiciones básicas, que difundieran las críticas, tanto en espacios públicos y privados; es así que las asociaciones y la prensa se convertirán en el eje articulador de la difusión de las ideas críticas al gobierno de turno. Solo de esta manera se generaría una corriente de opinión, los acontecimientos políticos y económicos de mediados del siglo XIX, posibilitaron tal desarrollo.

El país era campo fértil para la difusión de tales escritos e ideas, puesto que habíamos tenido una serie de gobernantes que habían constantemente hecho caso omiso a las demandas de la sociedad civil de aquellos años, no olvidemos que los caudillos durante la década de 1840 habían llevado al país a sus horas más aciagas haciéndolo prácticamente ingobernable. Ya habíamos tenido gobernantes que se habían arropado de una serie de prerrogativas, se habían olvidado de sus deberes y manejaban a la ciudadanía a su antojo. El irresponsable gasto fiscal del Estado era denunciado por esta opinión pública, por ello se exigía a los gobiernos de turno a implementar mejoras y evitar el despilfarro de las arcas del Estado (Contreras, 2015, p. 136). Esta génesis de la opinión incubo el escenario revolucionario de 1854, que se desencadeno durante el gobierno de José Rufino Echenique (1851-1854).

El año de 1854 fue un año muy complicado para el desarrollo de la institucionalidad del país, ya que el gobierno de turno había perdido la confianza de los diferentes sectores sociales, dando inició a la revolución liberal de ese año, que acabo con la corrupta e inmoral gestión de Echeni- 
que; esta situación obligo a impulsar las reformas en las instituciones, que era una exigencia de las actores políticos, el nuevo gobierno del general Ramón Castilla debía acometer tales pedidos, ya que iban en sintonía con la exigencia de la sociedad de pasar a una etapa de civilización y del progreso.

La Modernidad Tradicionalista: la crítica a la modernidad peruana

Para poder seguir analizando esta variable de las propuestas constitucionales de 1855 , se hace necesario presentar la idea de la modernidad tradicionalista, esto se demuestra con los escritores de la época, los cuales se encargaron de representar los vicios que tuvieron los gobiernos anteriores, había que apreciar había estado fallando en la construcción del orden republicano.

Uno de los pensadores que se acerca a esa descripción es Toribio Pacheco, destacado jurista de mediados del siglo XIX, quien durante los años de 1854 dirige el periódico El Heraldo. Él es testigo de los cambios por los que atravesó el país durante aquellos años, producto del progreso que trae consigo la era del guano. Este personaje esta insertado dentro del tradicionalismo modernista, el cual combina el conservadurismo de las clases dirigentes, junto con el liberalismo. Se trata ante todo de adaptar algunas ideas liberales a los intereses de la élite dirigente, aplicar el dogma liberal hubiera supuesto demoler el edificio tradicional del país. Pacheco desde este sistema tradicionalista modernista nos deja traslucir parte de ese imaginario político que plantea parte de las élites. En el plano económico es un ferviente seguidor de la economía política, donde su preocupación era la generación de la riqueza, esto se lograría con el concurso de la tierra, el trabajo y el capital; esto estimularía la circulación, la moneda, el gobierno y la educación. Dentro de Pacheco se ve el conflicto entre el libre comercio, impulsado por los liberales y el proteccionismo económico que es impulsado por los sectores tradicionales del país (Ramos Núñez, 2008, pp. 132 137).

En la ciudad de Arequipa, desde el peEn la ciudad de Arequipa, desde el periódico "El Heraldo" (1853), se publicó el texto "Cuestiones Constitucionales» el cual contiene la mentalidad política del proyecto tradicionalista modernista. Allí nos señala cómo debe organizarse el país, el Estado tiene un papel clave en el fomento de la seguridad, la educación, y la garantía de los derechos; para ello le otorga un papel importante al Poder Ejecutivo, ya que de él dependía la debida gobernabilidad del país (Ramos, 1993, pp. 176 - 177).

La propuesta de un Ejecutivo relativamente fuerte, pero que no llegue a la autocracia es parte del planteamiento de Pacheco, no debe imitarse modelos inaplicables a la realidad del país. Por ello critica la difusión de escritos que impulsan la idea de aplicar el régimen federal de los Estados Unidos, ya que la realidad de ese país es diferente a la nuestra, pues nuestra realidad tiene el drama de no tener una población alfabetizada, que no es consciente de la importancia de las instituciones políticas. Plantea que antes de pensar en cualquier proyecto que cambie el país, primero es necesario instruir a la población para que tome conciencia de los cambios que se necesiten, solo así se podría seguir el camino hacia el federalismo. El drama al interior del país es notorio, pues en los departamentos de la República no hay una población que se encuentre alfabetizada. Estas se encuentran expuestas a minorías, que de una u otra manera intentan imponer sus criterios a las mayorías, por lo tanto se establecerá una suerte de aristocracia que fue criticada por grupos opositores con lo cual los departamentos se convertirán en escenarios de luchas intestinas. En esas condiciones el Estado central se verá incapaz de tomar decisiones, entonces el sistema provincial de descentralización es una tentativa que no traería los resultados deseados. (Pacheco, 1854, pp. 119 - 122).

Otros escritos plantean que el sistema descentralizado es necesario para la buena gestión del Estado. Entonces para no caer en la ambivalencia del federalismo, se impulsa el sistema municipal, el cual debe ser independiente del poder central y tener recursos financieros que les permita impulsar el gasto público en obras para las poblaciones. La importancia de las municipalidades está en el hecho en que se tomaría en cuenta a las localidades, y ya no acosarían al Estado central con sus demandas. Otra ventaja es que el régimen municipal puede insertar a las poblaciones al conocimiento de la vida política, participar en los asuntos públicos, consiguiendo la posibilidad de poder insertarse en los manejos económicos de sus regiones; solo así se conseguiría la puesta en marcha del país, sin llegar a sacrificar los intereses de la nación en aras del federalismo. Esta propuesta liberal será adoptada en la Constitución de 1856, donde los títulos XIV y XV, destinados a las Juntas Departamentales y a las municipalidades, impulsaban el régimen descentralizado en el país. 
Análisis de la modernización económica del Estado por las propuestas liberales

Un punto importante de esta construcción del Estado es ver la política económica de la Convención $\mathrm{Na}$ cional, ya que la triunfante asamblea influenciado por la mentalidad reformista liberal, va en la búsqueda de la modernización económica y financiera del Estado peruano, por ello debía eliminarse los rezagos decadentes del antiguo régimen, de allí que se combatió la existencia de fueros personales y corporativos, la esclavitud, el tributo indígena, y de todas las cargas que pesaban sobre la tierra en forma de diezmos, censos, capellanías, vinculaciones, que frenaban y obstaculizaban la incorporación de la tierra y de la mano de obra hacia la economía librecambista capitalista.

Así mismo, el Estado, dentro de la reconstrucción de su autoridad intenta asumir las funciones de control demográfico, como por ejemplo el control del registro civil (García Jordán, 1991, p.99), la cual estaba en manos de la Iglesia Católica. Todas estas políticas implementadas por la Convención Nacional de 1855 lo llevarían a promover una política secularizadora, que complemente el crecimiento económico.

La agricultura era una de las principales actividades que tenía el país, era el sector económico que había sido fuertemente golpeado por la inestabilidad política, ello se manifestó en una severa depresión de ese sector. Por ello, era necesario plantear una serie de propuestas modernizadoras, así, se destaca la figura de Manuel Pardo, el cual en su estudio sobre la provincia de Jauja, señala que los liberales deseaban reformar la titularidad de la propiedad de las tierras agrícolas, que estaban en las manos muertas de la Iglesia, por ende, se debía apropiar de ellas, así se obtendría recursos fiscales para el Estado.

Con estos planteamientos se empezó a diseñar una política desamortizadora, que había empezado desde los primeros años de la república, pero será hará más agresiva desde la segunda mitad del siglo XIX. Esta circunstancia se manifestó cuando la Iglesia aprecio la intención del Estado de aplicar la expropiación de las capellanías, además de culminar con las vinculaciones, que la Constitución de 1856 lo ratifico en el artículo $\mathrm{N}^{\circ}$. 6: «En la república no se reconoce privilegios hereditarios, ni fueros personales, ni empleos en propiedad. Tampoco se reconocen vinculaciones, $\mathrm{y}$ toda propiedad es enajenable en la forma que determinan las leyes». Por este artículo no se menoscaba la jurisdicción sobre materia eclesiástica, que corresponde a los tribunales designados por las leyes canónicas; ni se autoriza para proceder a la detención ni a la ejecución de pena corporal contra personas eclesiásticas, sino conforme a cánones». Toda esta figura presentada, muestran las políticas que el Estado impulso: la eliminación del diezmo, primicias y derechos parroquiales; si bien estas disposiciones no pudieron aplicarse, pues la Convención fue cerrada en el año de 1857 , en los años siguientes finalmente se ejecutaran.

Esta eliminación de cargas fiscales realizadas por la Convención tendrá un impacto a futuro, esta razia fiscal, como denomina Carlos Contreras, dejó al Estado por completo a la suerte de los designios del guano; y como se estudió en el caso de Manuel Pardo había que buscar otras rutas para la diversificación y evitar la gran crisis que se avecinaba. Un problema constante que aqueja la situación económica y financiera, que concitó la atención de la Convención Nacional, fue el problema de la moneda feble que durante la etapa del funcionamiento de aquella institución, ocasionó grandes dolores a la economía y finanzas del país. Ante eso, el ministro de Hacienda Domingo Elías dispuso en 1855 la libre circulación de la moneda denominada cuatro arbolitos para luego devaluarlos a su cuarta parte de valor; pero la Convención no adoptó una posición con respecto a esta propuesta; lo único que genero fue más desconfianza hacia esa moneda (Salinas 2006, p. 71).

La crisis monetaria del Perú era grave y el gobierno de Castilla como la Convención Nacional no adoptaron una actitud fuerte para solucionar este pasivo que se había heredado desde la década pasada, este desorden pasa factura al comercio, los precios de los víveres y demás mercancías subieron dramáticamente, incluso para el año de 1857 había escasez monetaria debido en gran parte a la indecisión del gobierno. Hubieron advertencias al gobierno de Castilla de solucionar esta crisis, de no tomarse las recetas adecuadas podía colapsar el comercio nacional. El gobierno empezó a adoptar una serie de medidas para tratar de salvar la crisis del comercio, especialmente el de la zona sur.

Situación interesante es el panorama del comercio exterior del país el cual se ve estimulado por la demanda del mercado internacional, el cual hace crecer las exportaciones de las economías latinoamericanas desde mediados del siglo XIX (Bulmer-Thomas, 2010, pp. $62-63$ ) 
Tabla 1. Exportaciones Peruanas en la década de 1850.

Fuente: Un siglo a la deriva, Heraclio Bonilla.

\begin{tabular}{cccccccc} 
& \multicolumn{1}{c}{ Exportaciones Peruanas en Libras Esterlinas } & \multicolumn{2}{c}{ Cón } \\
Años & Guano & Salitre & Lanas & Corteza & Cobre & Algodón & Cueros \\
1850 & 964505 & 377737 & 126046 & 137758 & 20593 & 10464 & 18796 \\
\hline 1851 & 2227597 & 321131 & 265,41 & 76944 & 78285 & 5816 & 12409 \\
\hline 1852 & 956762 & 433603 & 259458 & 140817 & 41839 & 12683 & 11115 \\
\hline 1853 & 1285666 & 447976 & 270663 & 62744 & 89646 & 19278 & 8142 \\
\hline 1854 & 2544904 & 581783 & 186245 & 41482 & 14596 & 22388 & 5153 \\
\hline 1855 & 2943004 & 461019 & 203836 & 38258 & 45214 & 15806 & 10476 \\
\hline 1856 & 1523447 & 425076 & 368979 & 81931 & 137513 & 49232 & 12097 \\
\hline 1857 & 3397647 & 529878 & 342534 & 74996 & 113501 & 29057 & 28359 \\
\hline 1858 & 3693006 & 722191 & 339741 & 65555 & 223644 & 18,99 & 46598 \\
\hline 1859 & 838006 & 810986 & 386,84 & 32111 & 137758 & 23235 & 32767 \\
\hline 1860 & 1678349 & 1063741 & 350543 & 31,47 & 111623 & 20495 & 18991 \\
\hline
\end{tabular}

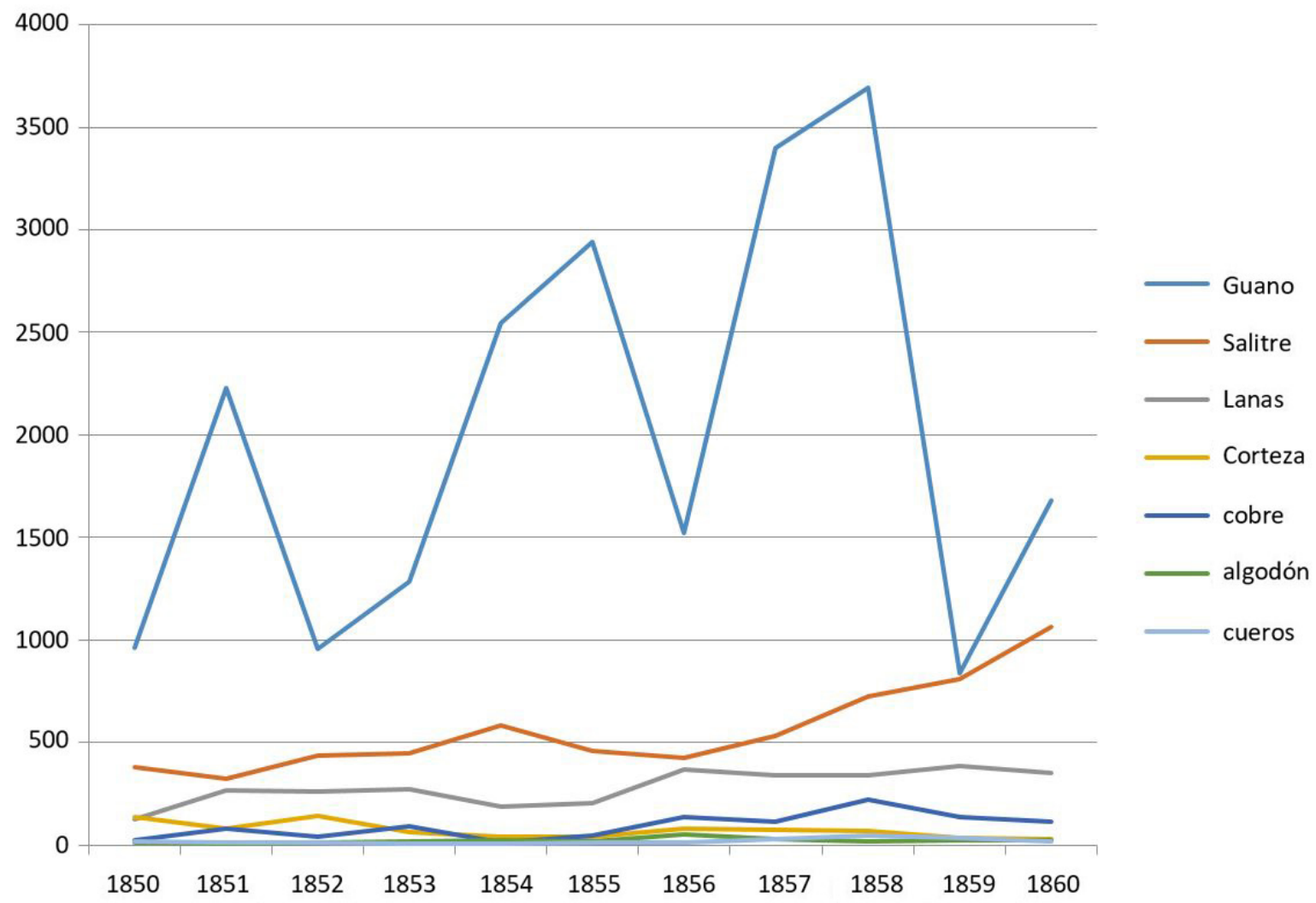

Figura 1. Exportaciones peruanas (1850 - 1860).

Fuente: Elaboración propia. 
En la Tabla 1 y Figura 1 se puede apreciar como las exportaciones peruanas de la década de 1850, tuvieron un despegue espectacular, en particular los recursos guaneros; la coyuntura política de 1855 afecto las exportaciones peruanas, el establecimiento de la Convención Nacional y la elaboración de la Constitución de 1856, afectara en la baja de las exportaciones, pero luego apreciamos como estas vuelven a subir. La promoción del liberalismo económico, fomento una política de crecimiento de las exportaciones, centrada principalmente en el guano; a pesar de todo, la modernización de la estructura económica y política del Estado era necesaria, por ello los planteamientos liberales eran las más pertinentes, para poder fomentar esta expansión económica. Las medidas impulsadas por la Convención de 1855, tanto las económicas, financieras, monetarias, apuntaron a una transformación parcial de la estructura económica del país.

\section{DISCUSIÓN}

La década de 1850 posibilito el éxito de las ideas liberales que de una y otra manera permitieron la modernización del Estado, como el establecimiento de la sociedad civil que puedo manifestar sus ideas en la prensa, con la finalidad de desarrollar la institucionalidad y la buscar el progreso, esto se expresó en la Constitución de 1856. Para lograr ese objetivo había que acabar con la precariedad política que había desgarrado al país, desde la independencia, y evitar los excesos, de la constitución centralista de 1839, la cual era criticada por su conservadurismo y autoritarismo presidencial.

El triunfo liberal de 1854, permitió el triunfo de aquellas ideas, las cuales van a impulsar la modernización del Estado. En ese sentido la clase inte- lectual peruana apuesta por construir la democracia liberal, difundiendo valores como el individualismo y libertades, con la finalidad de que el Estado busque la satisfacción de la necesidades de sus poblaciones. E los diferentes proyectos que se presentaron, se llega a plantear el federalismo, situación que será tomada en cuenta en la constitución de 1856 con las Juntas Departamentales. A pesar de estas propuestas, no se busca la modernización de la sociedad, el proyecto que se desarrolla es la «Modernización Tradicionalista», donde la idea del progreso occidental, significa reformar las instituciones políticas y económicas.

Se impulsa un nuevo código civil, comercial, nuevas normas legales, una nueva Constitución; pero el detalle es que no se impulsan reformas sociales, manteniendo la estructura social de dominación.

La modernización planteada por los reformistas constitucionales liberales establecía modernizar la vieja estructura económica, por ello la Constitución de 1856, busco eliminar privilegios corporativos que suponían una traba para la modernización del país, por ello era necesario impulsar medidas como la eliminación de los censos, diezmos, capellanías. Había que liberalizar la propiedad de la tierra, esto incide en la expansión económica de la costa, especialmente en Lima y el norte del país, donde empieza a dar un crecimiento económico; los ingresos del guano contribuyeron decididamente a estos cambios que afectan al país.

\section{REFERENCIAS BIBLIOGRÁFICAS}

Barrón, L. (2002). Republicanismo, liberalismo y conflicto ideológico en la primera mitad del siglo XIX en América Latina. En Jose Antonio Aguilar y Rafael Rojas (Coord.) El Republicanismo en Hispanoamérica. Ensayos de Historia intelectual y política. México D.F: FCE.

Bonilla, H. (1980). Un siglo a la deriva. Ensayos sobre el Perú, Bolivia y la guerra. Lima: IEP.

Rivera, E (1994). Perú: problema y posibilidad. Ensayo de una síntesis de la evolución histórica del Perú con algunas consideraciones cuarentaisiete años después. Fundación M. J. Bustamante de la Fuente, 4ta edición: Lima.

Bulmer-Thomas, V. (2010). La historia económica de América Latina desde la independencia. México D.F.: FCE.

Contreras, C. (2015). El Aprendizaje de la libertad. Historia del Perú en el siglo de su independencia. Lima: Fondo Editorial PUCP.

Dancuart, P. (1926). Crónicas Parlamentarias del Perú. Leyes resoluciones y decretos expedidos por la Convención nacional de 1855. Lima: Imprenta Americana Plazuela del Teatro.

Del Águila, A. (2013). La ciudadanía corporativa. Política, constituciones y sufragio en el Perú (1821-1896). Lima: IEP.

Tragzenies, F. (1992). La idea del derecho en el Perú republicano del siglo XIX .2da edición. Lima: PUCP.

Espinoza, J. (1855). Diccionario para 
el pueblo: Republicano democrático, moral, político y filosófico. Lima: Imprenta del Pueblo.

Ferrero, R. (2003). El liberalismo peruano. Contribución a una historia de las ideas. Lima, UNMSM/ULima.

Forment, C. (2012). La formación de la sociedad civil y la democracia en el Perú. PUCP :Lima .

García ,P. (1991). Iglesia y poder en el Perú Contemporáneo. Cuzco: CBC.

Gootenberg, P. (1997). Caudillos y Comerciantes. La formación económica del Estado Peruano (1820 - 1860). Cuzco: CEB

Jamanca, M. (2015). La Constitución inacabada. Ideas y modelos constitucionales en el momento fundacional del Perú primera mitad del siglo XIX. Lima: Universidad Nacional Mayor de San Marcos.

Masías, F. (1855). Breves nociones de la ciencia constitucionall. Imprenta de J. M. Masías.: Lima

Nájera, J. (1855). Cartilla del pueblo sobre principios democráticos. Imprenta de Eusebio Aranda : Lima.

Pacheco, T. (1854). Cuestiones Constitucionales. Imprenta de Francisco Ibañez y Herm :Arequipa.

Químper, J. (1854). Instrucción política y reformas para el Pueblo. Obra dedicada a las masas del Perú. Im- prenta de Francisco Ibáñez y hermanos: Arequipa.

Ramos, C. (1993). Toribio Pacheco. Jurista peruano del siglo XIX. Lima: PUCP.

Salinas, A. (2006). Cuatro billetes y crisis del sistema monetario peruano (1821 - 1879). Lima: IEP.

Sobrevilla, N. (2005). Conflicto regional, guano y poder. En P. Drinot y L. Garofalo (Eds.), Mas allá de la dominación y la resistencia estudios de historia peruana, siglos XVI - XX, (pp.181 - 214). Lima: IEP

Ulloa, J. (1854). El Perú en 1853. Un año de su historia contemporánea. París: Maulde y Renov. 